\title{
De la Mano Dura al Enfrentamiento Directo: vaivenes de las políticas públicas en El Salvador
}

\section{Revista de Sociologia e Política}

DOI 10.1590/1678-987319277102

\author{
Alberto Martínez-Reyes' (iD y \\ José Javier Navarro-Pérez" iD \\ Instituto Interuniversitario de Desarrollo Local, UV, Valencia, ES, España.

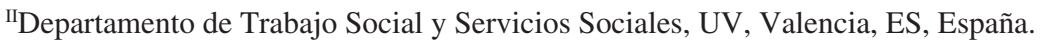

RESUMEN Introducción: El presente trabajo analiza las cuatro principales políticas públicas de seguridad contra las pandillas en EI Salvador: Mano Dura (2003-2004), Súper Mano Dura (2004-2009), Tregua entre pandillas (2012-2014) y Enfrentamiento Directo (2014-2019). El objetivo es identificar la influencia de estas políticas sobre la violencia. Materiales y Métodos: Se trata de una investigación cualitativa apoyada en 12 entrevistas y el relato de vida con las que se explora la responsabilidad gubernamental frente al problema de la violencia en El Salvador. El trabajo de campo se efectuó durante 7 meses, entre septiembre de 2016 y marzo de 2017. El tratamiento de la información se efectuó mediante software MAXqda 12. Resultados: El estudio constata 1) la influencia de las pretensiones electorales de los tomadores de decisiones en la elaboración de las políticas; 2) la poca planificación y discusión sobre el impacto de las acciones gubernamentales; y 3) el difícil escenario político y social que enfrentará El Salvador. Discusión: A partir de los resultados obtenidos y comparándolos con la literatura científica al respecto, se corroboran las aportaciones de los informantes que indican que las cuatro políticas implementadas han fracasado por la fragilidad democrática del país, las pretensiones electorales del partido político en el gobierno y por la poca capacidad de diseñar políticas públicas de calidad. Las cuatro políticas implementadas han tenido efectos contraproducentes y han permitido la expansión y reorganización de las pandillas y el recrudecimiento de la violencia.

Palabras Clave: políticas públicas; violencia; pandillas; seguridad pública; El Salvador.

Recibido en el 26 de Enero de 2018. Aprobado en el 18 de Diciembre de 2018. Acceptado en el 19 de Enero de 2019.

\section{Introducción ${ }^{1}$}

\begin{abstract}
${ }^{1}$ Agradecemos las sugerencias y comentarios de los dictaminadores anónimos de la Revista de Sociologia e Política.
\end{abstract}

${ }^{2}$ Lahera (2004) y Cardozo (2013) sostienen que las fases son: formulación, implementación y evaluación.
$\mathrm{L}$ as políticas públicas vienen configuradas por actividades concretas en torno a un objetivo que permita la satisfacción de necesidades de la ciudadanía (Layard 1980), y surgen de un proceso político que se concreta en una serie de decisionesacciones e incluso omisiones, asumidas por los gobiernos para responder a los problemas públicos que enfrenta la sociedad (Cardozo 2013). Ahora bien, debemos aclarar que estas definiciones se centran en un tipo de política pública ideal, o lo que Lahera define como política pública de calidad; es decir, que incluya "orientaciones o contenidos, instrumentos o mecanismos, definiciones o modificaciones institucionales, y la previsión de sus resultados" (2004, p. 8).

Pero en la práctica estas definiciones tienen algunos errores, porque las políticas públicas implementadas no siempre son de calidad y no siempre cumplen con las fases que plantean algunos autores ${ }^{2}$. Idealmente, las políticas públicas deberían de buscar el interés común; pero siguiendo a Velásquez, "en el mundo real de las políticas, encontramos algunas que se alejan de lo público o del interés común, porque grupos particulares permean las esferas de poder para obtener, a través de la política, una ventaja en desmedro de los intereses de una colectividad" (2009, p. 151). 
${ }^{3}$ Alianza Republicana Nacionalista.
En El Salvador la elaboración e implementación de las políticas públicas ha estado muy alejada de la calidad. El Programa de Naciones Unidas para el Desarrollo (PNUD), sostiene que las políticas públicas salvadoreñas han fracasado, entre otras cosas, por estar mal concebidas, consecuencia de la débil institucionalidad política y por la baja exigencia de la burocracia (2013). En este escenario, cada actor intenta salvaguardar sus intereses. Esto es lo que ha pasado en las políticas públicas de seguridad en El Salvador: aunque se han promovido como respuesta a un problema, que desde finales de los noventa han sido las pandillas, han intervenido diferentes actores con intereses propios o han sido elaboradas por "el proyecto político personal de quien gobierna y por los compromisos electorales adquiridos en las elecciones" (Medellín 2004, p. 43).

El Salvador ha vivido diversos episodios de violencia, más o menos prolongados, en los que la falta de planificación, la debilidad institucional, los conflictos de intereses y la poca voluntad política han sido los elementos comunes presentes en las respuestas gubernamentales. El actual conflicto social que enfrenta el país encuentra su causa más superficial en el año 2003, con el lanzamiento de una serie de acciones contra las pandillas que mediáticamente se conoció como "Mano Dura".

La Mano Dura se ejecutó en la última etapa del gobierno de Francisco Flores, unos meses antes de las elecciones presidenciales y fue una estrategia política que le permitió al partido ARENA $^{3}$ afianzarse con el poder por cinco años más (Martínez-Reyes \& Navarro-Pérez 2018). La Mano Dura es uno de los ejemplos de cómo se han elaborado las políticas públicas en materia de seguridad. Los tres gobiernos subsecuentes elaboraron, bajo el mismo esquema, sus políticas públicas de seguridad: Súper Mano Dura (2004-2009); Tregua (20121014); Enfrentamiento directo (2014-2019). Todas éstas políticas fracasaron y se han planteado en el extremo más alejado de una política pública de calidad. Todas se han basado en pretensiones electorales, han tenido poca transparencia, tres de ellas han sido represivas y todas han estado plagadas de ilegalidades. Pero lo más importante es que lejos de frenar la violencia y controlar la seguridad pública, han fortalecido y expandido a las pandillas, sumiendo al país en una profunda crisis social.

En este artículo presentamos y analizamos las políticas públicas contra la violencia de las pandillas en El Salvador, desde el año 2003 al 2014, y cómo éstas han sido catalizadoras en el incremento de la violencia en el país; todo esto con el propósito de dar respuesta a nuestras preguntas de investigación: ¿Cuáles han sido los errores de las políticas públicas contra la violencia que han favorecido el aumento inmediato o posterior de muertos? ¿Ha sido posible alcanzar un acuerdo político en torno a las actuaciones del gobierno contra las pandillas? Y en este sentido, ¿podemos identificar la existencia de alternativas para superar la violencia?

\section{I.1 Políticas Públicas en El Salvador}

Uno de los principales debates en torno a las políticas públicas se centra en las consecuencias negativas generadas por las medidas represivas ejecutadas como respuestas al problema de seguridad (Heinze \& Armas 2015). Países como México, Brasil, Colombia, Puerto Rico y el ejemplo más actual: Filipinas, han implementado éstas medidas con resultados adversos. En esta línea, Jütersonke, Muggah \& Rodgers (2009) han demostrado que las acciones represivas radicalizan a las pandillas, empujándolas hacia formas más organizadas de criminalidad.

De acuerdo a Sanjurjo (2016), las políticas de seguridad en Latinoamérica suelen ser deficientes, contienen fallos en su implementación, están cargadas de 
${ }^{4}$ Las elecciones en El Salvador son cada tres y cinco años. Tres años para las elecciones municipales y legislativas, y cinco años para las elecciones presidenciales. efectos perversos y algunas veces tienen consecuencias no deseadas. México, Brasil y El Salvador han centrado sus políticas en las detenciones masivas contra las pandillas, lo que ha llevado a establecer "pandillas carcelarias". En los tres casos, las pandillas carcelarias han logrado una expansión sin precedentes de su poder en las calles, barrios y comunidades (Lessing 2017). En el caso de Puerto Rico, la implementación de medidas represivas dio como resultado "la concentración de la violencia dentro de las comunidades más pobres y expuso a sus residentes a mayores peligros en manos de la policía y los ciudadanos puertorriqueños" (LeBrón 2017, p. 14). Es decir, la represión, la falta de planificación y estudios de impacto son algunos elementos comunes presentes en las políticas públicas de seguridad en Latinoamérica.

Otro elemento a tomar en cuenta en la forma de hacer políticas públicas en países con democracias débiles es el concepto de ciclos electorales, es decir, "de qué manera el ritmo constante de la competencia política, determinado por la sucesión de plazos electorales, puede tener un efecto tanto en la amplitud como en el contenido de la agenda gubernamental" (Surel 2006, p. 58). Un efecto del ciclo electoral que puede extrapolarse a El Salvador es que al acercarse cada periodo electoral, los actores políticos muestran su receptividad clientelar y masa votante a determinadas reivindicaciones con objeto de acercarse a la ciudadanía y en esta línea, abanderar necesidades ciudadanas y sustentar programas políticos con el ánimo de asegurar apoyos electorales. En El Salvador ha sido recurrente que en los periodos electorales ${ }^{4}$ se movilicen cambios sustantivos y planteamientos que influyen o tratan de mediar en la intención del voto (Muñoz 2011). El ejemplo más claro de esto es el lanzamiento del Plan Mano Dura del año 2003, el cual se lanzó faltando unos meses para finalizar el período presidencial del presidente Flores, y tuvo como propósito afianzar al partido ARENA en las opciones de voto (Bruneau 2014).

La Mano Dura puede resumirse como una política represiva en contra de las pandillas y se basó fundamentalmente en detenciones masivas y en el incremento de penas contras los miembros de las pandillas (Meyer \& Seelke 2011), por lo que encontró un rechazo inmediato del principal partido de oposición y de diversos sectores de la sociedad. El rechazo se centró, sobre todo, en las violaciones a los derechos humanos. Como es sabido, encontrar oposición con una política pública puede llevarla al fracaso. De acuerdo a Vilas (2011, p. 5):

Una política que no tenga en cuenta los relieves del mapa político - es decir, las tensiones y conflictos entre los principales actores sociales afectados de una $\mathrm{u}$ otra manera, la opinión pública y los humores de la sociedad- tiene pocas probabilidades de ser eficaz en el logro de sus objetivos, independiente de la calidad de su diseño técnico e incluso de la movilización de recursos coercitivos.

A este respecto, Medellín (2004, p. 43), al referirse a las políticas públicas en los países de frágil institucionalización, como podría ser El Salvador, considera que la estructuración de las políticas públicas:

están en un primer momento sobredeterminadas por la voluntad y la intención particular de aquellos que están al frente de las instituciones públicas. Pero posteriormente son sometidas a complejos procesos de negociación de intereses internos y externos al gobierno. En la medida que la negociación va filtrando el aparato gubernamental, las intermediaciones de intereses privados se multiplican en un escenario cada vez más conflictivo y fragmentado.

En esta línea argumental Aguilar \& Lima (2009, p. 2), planteándose la forma de hacer políticas públicas en Latinoamérica, sostienen que "los gobiernos no son los únicos actores en la implementación de políticas, si bien toda política pública es una acción de gobierno desarrollada a través de decretos y reglamentos, que no se reducen en exclusiva a esto"; porque las políticas van más allá de 
${ }^{5}$ Frente Farabundo Martí de Liberación Nacional. una mera acción gubernamental. En El Salvador, gobernar por leyes y planes, y promover éstos como políticas públicas, ha sido un método recurrente.

Los gobiernos posteriores al de la Mano Dura siguieron con esta forma de hacer políticas públicas. El gobierno de Antonio Saca (2004-2009), fortaleció la política de su antecesor y la denominó como "Súper Mano Dura”. Esta política tuvo como pilares la detención masiva de jóvenes pandilleros y no pandilleros, el uso del ejército en tareas de seguridad pública y el combate frontal a las pandillas (Aguilar, 2006). El primer gobierno de izquierda (2009-2014), liderado por el $\mathrm{FMLN}^{5}$, inició con una postura represiva pero al poco tiempo elaboró una "Tregua". La política de la tregua fue diseñada por el gobierno salvadoreño y en ella se negoció con las pandillas la reducción de homicidios a cambio de concesiones y beneficios como el traslado de cárceles de máxima seguridad a prisiones más flexibles; la disminución de patrullajes y detenciones de pandilleros; el ingreso de objetos prohibidos a las cárceles, tales como móviles, aparatos eléctricos; y otras prebendas (Cruz y Durán 2016). Aunque los homicidios se redujeron, detrás de esta política hubo corrupción, ilegalidades y fortalecimiento de las pandillas. El actual gobierno, también liderado por el FMLN (2014-2019), ha abanderado el "Enfrentamiento Directo" con las pandillas, que ha tenido como elementos principales: el incremento de los efectivos militares en tareas de seguridad pública; reformas legales para incrementar la persecución penal de las pandillas; toma de control de las cárceles; creación de grupos mixtos (militares y policías) para combatir a las pandillas, enfrentamientos armados con un incremento exponencial de la inseguridad de la ciudadanía, convertida en víctima vulnerable del conflicto (Reyna 2017). Los resultados de estas acciones han sido incrementar los niveles de violencia, homicidios, desplazamientos forzados, violaciones a los derechos humanos y el resurgimiento de grupos de exterminio.

\section{I.2 Seguridad pública: El Salvador y la relación entre políticas, políticos y pandillas}

La idea de seguridad pública implica principalmente el mantenimiento del orden público, es decir, una situación de tranquilidad y paz social establecida institucionalmente por medio de la imposición de la ley. Así, los instrumentos argumentales de la seguridad pública se identifican a partir de la presencia policial, la independencia de los jueces y la articulación del sistema penitenciario que asegure a la población reclusa en correccionales (Dammert 2012).

Contextualizando la seguridad pública en Latinoamérica, Briceño \& Zubillaga resaltan la ausencia de una plataforma básica de seguridad y de la efectiva aplicación de las leyes. Contrario a esto, plantean los autores, lo que se ve es una "preocupante situación donde la severidad de los castigos, la estimulación de la venganza ciudadana y el surgimiento o resurgimiento de grupos de exterminio se ve apoyado por los hacedores de políticas públicas" (2002, p. 34).

La seguridad pública en los países con democracias débiles se ve mermada por factores como la corrupción, el narcotráfico, las políticas públicas mal implementadas, entre otros (Hegre 2014). En Brasil, por ejemplo, la seguridad ciudadana conjuga una relación entre el Estado, las organizaciones criminales y el capital privado (Garmany \& Galdeano 2017). En el caso mexicano, la seguridad pública pasó de la guerra contra el narcotráfico a ser controlada por otros actores: bandas paramilitares involucradas en el vigilantismo, ejércitos privados y fuerzas de seguridad privadas que trabajan para redes globalizadas de las industrias de drogas, armas y tráfico humano (Speed 2016).

En el caso salvadoreño, el Estado no ha podido garantizar ni tener el control de la Seguridad Pública, la cual ha pasado a centrarse, principalmente, en las pandillas. Se estima que en El Salvador hay de 30.000 a 60.000 pandilleros y 
${ }^{6}$ La Asociación de Transportistas de El Salvador estima que en 2014 pagaron $\$ 30$ millones a los pandilleros. cerca de medio millón de personas vinculadas a ellos (López et al. 2017). Las dos agrupaciones principales son la Mara Salvatrucha y la pandilla Barrio 18 (que está divida en dos grupos: los Sureños y los Revolucionarios). Existen otras pandillas con influencia inferior como la Mara Máquina, Mao-Mao, Mirada Locos, pero la incidencia de estas es menor y no se han expandido a todo el territorio salvadoreño.

La principal fuente de financiación de las pandillas es a través de la extorsión (Gómez 2013). Estas cobran una tasa a comerciantes y transportistas que funcionan en el territorio que "dominan" ". Un estudio de Comisión Española de Ayuda al Refugiado (CEAR 2013), respalda que las maras y pandillas obtienen recursos a través de sus actividades, principalmente de la extorsión, el sicariato y la venta de armas y drogas. Además, "la preeminencia de una u otra fuente varía en función de la mara o pandilla en concreto, e incluso de la clica de la que se trate" (CEAR 2013, p. 25). En esta línea argumentaría, Andrade (2015) informa que la extorsión en El Salvador inyecta, mediante captación ilegal de fondos y en especie, un peligro real y supra potencial que encarnan los grupos delincuenciales organizados. Desde esta perspectiva, Martel (2006) refiere que las pandillas fracturan el control social y generan inseguridad y una constante situación de amenaza, que prácticamente se integra en las formas de vida cotidiana.

Las pandillas de hoy lucen diferentes a las que formaron parte apenas un lustro. La rebelión de los rangos menores y más jóvenes ha tomado mayor control sobre las operaciones (Santos 2014). Este cambio dentro de la estructura, organización y relaciones dentro de la pandilla fue motivado por las detenciones y encarcelamientos masivos realizados por las políticas represivas (Peetz 2010). Esta tesis es compartida por Kinosian (2016, p. 9) al interpretar que "los líderes encarcelados de las pandillas fueron transferidos de vuelta a prisiones de máxima seguridad, se interrumpiósu comunicación con los miembros de la calle, y los desencantados miembros de rango medio asumieron mayor control". En este contexto, las pandillas controlan comunidades enteras y desafían los mecanismos de control legal y de seguridad institucional.

Las pandillas han establecido un control geográfico que condiciona el ámbito local, su desarrollo y la vida pública salvadoreña. Asesinatos, desapariciones, extorsiones, agresiones, amenazas, son términos que forman parte de la herencia de la guerra civil (Binford 2002) y que actualmente delimitan el imaginario colectivo.

Desde 2003, los gobiernos salvadoreños no han podido garantizar la Seguridad Pública y han implementado políticas públicas poco discutidas, con mucha oposición de los partidos políticos y de la sociedad civil, pobremente evaluadas, con resultados totalmente contrarios a los esperados y cargadas de ilegalidades (Savenije 2014).

\section{Metodología}

\footnotetext{
7 La cuestión de la violencia es un tema incómodo, delicado, que preocupa y perturba tanto a la sociedad como la vida cotidiana en El Salvador. Esto inquietó a los informantes. Esta investigación que proyecta un
}

Nos hallamos ante un proceso metodológico complejo, no tanto por la instrumentalización de las técnicas, sino por el objeto de estudio que presenta este trabajo ${ }^{7}$. Partimos de un enfoque metodológico cualitativo, en la línea de Creswell (2006), a efectos de descubrir, explicar, argumentar las distintas visiones del conflicto. Las técnicas de aproximación empírica fueron la realización de entrevistas a informantes clave - expertos y la aproximación a la realidad de los pandilleros mediante relatos de vida. Con objeto de garantizar la objetividad al estudio, seguimos las alineaciones de Denzin (1970) a los efectos de triangular las técnicas de investigación. 
estudio original, ha estado plena de obstáculos desde prácticamente su diseño; en el inicio del proceso de selección de las personas, logramos evidenciar el miedo existente para hablar sobre las actuaciones del Estado, la violencia y las pandillas en El Salvador. Encontramos elementos que dificultaron la selección de los participantes y que pudieron distorsionar el trabajo de campo. Por una parte, los pandilleros no gozaron de autorización para hablar, mucho menos de aportar su experiencia vital y visión dentro de la pandilla, y quien asumió ese riesgo lo hizo por convicciones personales que suponen una actuación de insubordinación a la jerarquía de la pandilla, que acarrea consecuencias: palizas, amenazas e incluso la muerte. Por otra parte, otros pandilleros que estuvieron dispuestos a hablar solicitaron un tipo de remuneración económica, ajena a nuestra visión ética del proceso empírico. Finalmente, tal como se explica en las técnicas utilizadas, realizamos y acabamos doce entrevistas y seis relatos de vida.
El diseño metodológico, se realizó con el propósito de alcanzar los siguientes objetivos:

1. Examinar las cuatro políticas públicas en la lucha contra la violencia en El Salvador implementadas entre los años 2003 al 2014

2. Identificar los elementos de estas políticas que han permitido el mantenimiento e incremento de la violencia y la presencia de las pandillas en la esfera pública

Con este propósito, se realizaron 12 entrevistas; los informantes se seleccionaron con heterogeneidad, atendiendo a criterios de extensión discursiva y percepción de la realidad compleja de Milliken (1999). Nos interesó seguir las orientaciones de LeGreco \& Tracey (2009), yuxtaponiendo unos y otros informantes, con objeto de dotar de heterogeneidad al plano discursivo. La Tabla 1 muestra las referencias de los entrevistados.

Por otro lado, se trató de homogeneizar el número de entrevistados expertos con el de los pandilleros a los que se les realizó el relato de vida; si bien la complejidad de la jerarquía y sometimiento a la pandilla, dificultaron esta tarea e impidió cumplir con este objetivo. Así, se iniciaron 17 relatos, 9 pudieron ser contactados. De estos, finalizamos 6 que fueron categorizados posteriormente, para ser implementados como cuerpo empírico del presente trabajo. Todos los relatos autobiográficos fueron identificados con códigos neutros para caracterizar su procedencia pero evitar su identidad. Desde los planteamientos de responsabilidad ética de Dresser (1998), se obtuvo el consentimiento informado de todos los sujetos, a efectos que estos decidiesen autónoma, libre y voluntariamente su participación en la investigación. A los efectos de obtener una muestra de sujetos para abordar los episodios vitales, seguimos las recomendaciones de Jolly (2001) sobre heterogeneidad y número, centrando la idoneidad de la autora en el intervalo de 5-8 sujetos y las distintas sensibilidades tanto ideológicas como de procedencia, con objeto de analizar la transversalidad de los discursos. Finalmente se completaron 6 relatos. La siguiente Tabla 2 presenta los relatos que pudieron confirmarse.

Tabla 1 - Desarrollo de las entrevistas

\begin{tabular}{lllccc}
\hline $\mathbf{N}^{\circ}$ & Fecha & Informante & Código & Medio & Duración \\
\hline 1 & Septiembre 2016 & Investigador sobre Derechos Humanos & DH-1 & Presencial & $1: 10: 57$ \\
2 & Septiembre 2016 & Periodista en activo & PER-1 & Presencial & $1: 28: 36$ \\
3 & Septiembre 2016 & $\begin{array}{l}\text { Representante de una organización vinculada al } \\
\text { proceso de tregua con las pandillas }\end{array}$ & RT-1 & Skype & $46: 36$ \\
& & & & \\
4 & Septiembre 2016 & Profesora Universitaria & PU-1 & Presencial & 56.22 \\
5 & Octubre 2016 & Representante de Agencia de Cooperación & COP-1 & Presencial & 41.12 \\
6 & Noviembre 2016 & Representante de una organización salvadoreña & ORGF-1 & Presencial & $28: 25$ \\
& & feminista & & & $29: 19$ \\
7 & Noviembre 2016 & Miembro de la Fuerza Armada & FA-1 & Skype & $39: 26$ \\
8 & Noviembre 2016 & Miembro de la Policía Nacional Civil & POL-1 & Skype & Skype \\
9 & Diciembre 2016 & Fiscal & FIS-1 & S2:56 \\
10 & Febrero 2017 & Representante del ISNA* & ISNA-1 & Skype & $1: 09: 53$ \\
11 & Marzo 2017 & Periodista en activo & PER-2 & Skype & $58: 36$ \\
12 & Marzo 2017 & Representante del Ministerio de Justicia y & MJ-1 & Skype & $1: 26: 14$ \\
& & Seguridad Pública & & & \\
\hline
\end{tabular}

Fuente: Los autores.

"Instituto Salvadoreños de la Niñez y la Adolescencia. 
Tabla 2 - Codificación de relatos de vida

\begin{tabular}{llccc}
\hline Fecha & Informante & Código & Medio & Duración \\
\hline Septiembre 2016 & Pandillero B-18 Sureños & PBS-1 & Presencial & $45: 06$ \\
Octubre 2016 & Pandillero B-18 Sureños & PBS-2 & Presencial & $51: 44$ \\
Octubre 2016 & Pandillero B-18 Revolucionarios & PBR-1 & Presencial & $36: 15$ \\
Octubre 2016 & Pandillero MS-13 & PMS-1 & Presencial & $46: 06$ \\
Enero 2017 & Pandillero alto grado MS-13 & PMS-2 & Skype & $1: 46: 23$ \\
Marzo 2017 & Pandillero Mao-Mao & PMao-1 & Skype & $35: 45$ \\
\hline
\end{tabular}

Fuente: Los autores.

El trabajo de campo se efectuó durante 7 meses, entre septiembre de 2016 y marzo de 2017. Los encuentros con informantes fueron en algunos casos presencialmente y en otros, mediante software de comunicación Skype.

El tratamiento de la información se efectuó mediante software de tratamiento cualitativo MAXqda 12. Se establecieron dos estructuras de análisis, a partir de texto y concepto. Ello permitió la construcción de redes discursivas y la lógica articulación compleja integrando los niveles de abstracción. Utilizamos el modelo de intersección crítica de categorías (Wodak \& Meyer 2009) recogidas en segmentos explicativos o de alusión a ellas, tal como los informantes clave verbalizaron. Se trabajó con 317 segmentos que referenciaron las categorías extraídas tanto de las entrevistas como de los relatos de vida; algunos de ellos, se incorporaron al presente trabajo (Tabla 3).

El proceso de categorización se articuló a partir de la propuesta de Patton (1990), realizando entrevistas apoyadas en un guion que abordó distintas áreas de conceptuales y que posteriormente se diseccionaron en categorías y subcategorías de análisis. Esta preservación se moduló en ambas técnicas. Con este objeto se secuenciaron las siguientes categorías: políticas públicas de seguridad, democracia estructural, pandillas - ideologías y violencias, seguridad

Tabla 3 - Codificación de entrevistados y relatos de vida en segmentos discursivos

\begin{tabular}{lcc}
\hline Técnicas & Codificaciones & Segmentos \\
\hline Entrevistas & DH-1 & 7 \\
& PER-1 & 3 \\
RT-1 & 2 \\
MJ-1 & 6 \\
ORGF-1 & 3 \\
& FA-1 & 0 \\
POL-1 & 4 \\
& FIS-1 & 2 \\
COP-1 & 2 \\
& PU-1 & 4 \\
& ISNA-1 & 3 \\
Relatos de vida & PER-2 & 2 \\
& PBS-1 & 1 \\
& PBS-2 & 3 \\
& PBR-1 & 4 \\
Total & PMS-1 & 2 \\
& PMS-2 & 3 \\
& PMao-1 & 2 \\
& 18 & 53 \\
\hline
\end{tabular}

Fuente: Los autores. 
pública, propuestas de solución y reinserción. Para este artículo, presentamos las cinco primeras que mostramos en el cuadro descriptivo (Tabla 4 y Tabla 5).

\title{
III. Resultados
}

Hemos dividido los resultados en función de los objetivos con los que se diseñó la investigación. Bajo estos parámetros presentamos los hallazgos más relevantes.

\section{III.1 Populismo electoral}

Los informantes destacan la ausencia de consenso institucional en las políticas contra la violencia. La respuesta de las políticas públicas al crimen ha sido muy negativa. Esto se ha extendido en el tiempo debido a la ausencia de diálogo entre las diferentes fuerzas políticas, tanto opositoras como las instauradas en el poder. La nulidad de consenso ha reforzado al crimen y disparado el discurso populista para acabar con éste. En este sentido, los informantes reiteraron que:

\begin{abstract}
"Nunca hubo proyecto político contra las pandillas. Un grave problema que tenemos en nuestro país. Debiera haber un pacto de estado sobre estos grandes problemas que nos acostumbran a vivir con miedo" (PER-2)

"Mientras los grandes partidos no se pongan de acuerdo no habrá políticas. Habrá ahora represión, ahora tregua, ahora muertes, ahora abusos e intimidación del estado, ahora quiero decirle, una montaña con picos: ahora tranquilidad, ahora conflictos pero los muertos siguen" (ISNA-1)

"Todos los gobiernos empiezan con cosas diferentes borran todo lo que hizo el anterior y así Ellos son los que no se ponen de acuerdo, y lo que hacen es darnos mecha. Si ellos nos matan, nosotros nos defendemos, ¿me entendés? (PMao-1)
\end{abstract}

Las políticas públicas han sido motivadas por pretensiones electorales y no tanto por el convencimiento político de acabar con la violencia. Desde el 2003, los gobiernos han utilizado la lucha contra las pandillas como su bandera política para captar votos. El discurso de los informantes informó a este respecto:

"Entonces sería muy difícil de hablar de políticas públicas cuando lo que hemos visto es politiquería, todo es en función de las elecciones, aquí se van cambiando los discursos en función de las elecciones" (DH-1)

"Primeramente quiero decirte que desde que yo estoy en el Ministerio de Justicia desde el 96, más o menos $Y$ desde mi punto de vista, te equivocás cuando me preguntás por las políticas. No ha habido políticas de seguridad. Al contrario, éstas han sido estrategias o acciones que se han llevado a cabo para un problema en específico que es el de las pandillas y con un interés netamente electoral.” $(M J-1)$

El populismo y las acciones mediáticas se convirtieron en las acciones predilectas para enfrentar el fenómeno de las pandillas en los últimos cuatro gobiernos. Las dos primeras políticas fueron la Mano Dura y la Súper Mano Dura. La primera fue motivada por pretensiones electorales ya que se lanzó a solo unos meses de finalizar el período presidencial de Francisco Flores. Por otra parte, fue criticada y encontró mucha oposición por su carácter populista y por estar plagada de ilegalidades y violaciones a los derechos humanos:

"Populista, sí. Y además de populista fue una forma de ganar votos” (DH-1).

"Fue un engaño un abuso de poder. Con ese eslogan de "política pública" sin la aquiescencia necesaria con otros partidos, estaba destinada a fracasar" (PU-1)

"De pronto Flores se inventó un plan ni él se creía el resultado final” (COP-1) 
Tabla 4 - Modelo para establecer las categorías y subcategorías derivadas de los informantes clave

\begin{tabular}{|c|c|c|c|c|c|}
\hline $\mathrm{N}^{\circ}$ & Área & Informante & Código & Categorías & Subcategorías \\
\hline 1 & Seguridad & Miembro de la Fuerza Armada & FA-1 & 1. Políticas públicas de seguridad & 1.1.- Manos Duras \\
\hline 2 & & Miembro de la Policía Nacional Civil & POL-1 & & 1.2.- Tregua entre pandillas \\
\hline 3 & & $\begin{array}{l}\text { Representante del Ministerio de Justicia y } \\
\text { Seguridad Pública }\end{array}$ & MJ-1 & & 1.3.- Enfrentamientos con pandillas \\
\hline 4 & Justicia & Fiscal & FIS-1 & & 1.4.- Elecciones \\
\hline 5 & Derechos Humanos & Investigador de Derechos Humanos & $\mathrm{DH}-1$ & & 1.5.- Políticas mal planificadas \\
\hline 6 & $\begin{array}{l}\text { Organizaciones No } \\
\text { Gubernamentales }\end{array}$ & $\begin{array}{l}\text { Representante de una organización salvadoreña } \\
\text { feminista }\end{array}$ & ORGF-1 & & 1.6.- Seguridad pública \\
\hline 7 & & Representante Agencia Cooperación & $\mathrm{COP}-1$ & & 1.7.- Ciclos electorales \\
\hline 8 & & $\begin{array}{l}\text { Representante de una organización vinculada al } \\
\text { proceso de tregua con las pandillas }\end{array}$ & RT-1 & 2. Fragilidad democrática & 2.1.- Corrupción \\
\hline 9 & Medios de comunicación & Periodistas en activo & PER-1 & & 2.2.- Populismo punitivo \\
\hline 10 & & Periodistas en activo & PER-2 & & 2.3.- Respuesta mediáticas \\
\hline 11 & Educación & Profesora Universitaria & PU-1 & & 2.4.- Negociaciones con pandillas \\
\hline \multirow[t]{12}{*}{12} & $\begin{array}{l}\text { Instituciones } \\
\text { Gubernamentales }\end{array}$ & $\begin{array}{l}\text { Representante Inst. Salvadoreño Niñez y } \\
\text { Adolescencia (ISNA) }\end{array}$ & ISNA-1 & 3. Funcionamiento de las pandillas & 3.1.- Extorsión \\
\hline & & & & & 3.2.- Evolución de las pandillas \\
\hline & & & & & 3.3.- Gestión desde prisiones \\
\hline & & & & & 3.4.- Control territorial \\
\hline & & & & 4. Planes de seguridad & 4.1.- Presencia de las fuerzas de seguridad \\
\hline & & & & & 4.2.- Militarización de la seguridad pública \\
\hline & & & & & 4.3.- Ausencia de programas de reinserción \\
\hline & & & & 5. Conflictos & 5.1.- Enfrentamientos con pandillas \\
\hline & & & & & 5.2.- Represión \\
\hline & & & & & 5.3.- Escalada de violencia \\
\hline & & & & & 5.4.- Medidas extraordinarias \\
\hline & & & & & 5.5.- Fortalecimiento de las pandillas \\
\hline
\end{tabular}


Tabla 5 - Disección de categorías y subcategorías de análisis de relatos de vida

\begin{tabular}{ll}
\hline Categorías & Subcategorías \\
\hline 1.-Políticas públicas contra las & 1.1- Uso de la violencia para ejercer poder \\
pandillas & 1.2.- Políticas populistas \\
& 1.3.- Intereses electorales \\
2.-La política y las pandillas & 2.1.-Represión \\
& 2.2.- Fortalecimiento pandillas \\
& 2.3.- Beneficios a pandillas \\
2.4.- Negociación gobierno/pandillas & 3.1.- Prevención y reinserción \\
3.-Estrategias contra las & 3.2.- Ejecuciones extrajudiciales \\
pandillas & 3.3.- Detenciones masivas \\
\hline
\end{tabular}

Fuente: Los autores.

"La Mano Dura fue una farsa Eso no fue Mano Dura, eso fue un show para ganar las elecciones del 2004, fue algo populista. ¿Quién podía tragarse que Flores sacara una política cuando le faltaban meses para terminar?” (MJ-1)

Antonio Saca continuó en la misma línea de la política de seguridad de su antecesor Francisco Flores. La política Súper Mano Dura, al igual que la anterior, evidenció ilegalidades y fue extremadamente populista. ARENA, captó a su electorado centrándose en el tema de la seguridad y el control sobre las pandillas. Sin embargo, no previeron el efecto negativo que tendrían las detenciones masivas en las prisiones y en la organización de las pandillas.

"Yo en particular, el "manodurismo" lo considero una sola pieza. Porque Flores no hizo nada, lanzó el monstruo y se fue. Ni a él se le habrá ocurrido esa Mano Dura seguramente" (PER-1)

"No podemos tildarlo de política contra las pandillas. Hay que considerarlo como lo que fue: un desastre" (POL-1)

"La Súper Mano Dura fue lo mismo que la anterior pero jodiendo más a los bichos, metiéndolos más tiempo Y todo el sistema se vino abajo. Falta de fiscales y jueces. No había espacio en la cárcel” (MJ-1)

"Mirá, el gobierno nos tiene bien socados, pero ni así puede frenar al barrio nos mantenemos con que los hommies recogen. Las líneas salen de dentro" (PBS-2)

El fracaso del partido ARENA en materia de seguridad expresado con la reorganización de las pandillas, su fortalecimiento, el incremento en los niveles de la violencia y en el número de los homicidios, entre otros factores, llevaron al FMLN a ganar las elecciones presidenciales del año 2009. Los cambios ofrecidos en el programa de gobierno del presidente Mauricio Funes generaron expectativas en la población. El problema para el gobierno del FMLN se centraba en que las pandillas ya no eran las mismas de la década pasada, las de 2009 eran grupos más organizados y controlaban comunidades y territorios. Después de seis años de represión las pandillas se habían fortalecido y habían establecido jerarquías y contactos a nivel nacional.

“¿Qué hacían con todo ese tiempo? Planear, organizarse, unirse más, volverse fuertes, hacer pactos entre ellos Eso hicieron estos hijos de puta. Antes las pandillas actuaban muy a lo loco ¿qué pasó después? Las pandillas empezaron a actuar bajo liderazgos". (MJ-1)

"Nosotros tenemos códigos internos y hay que cumplirlos. Desde el más morrito al más viejo tienen que cumplir. Y también códigos externos, vos no podés ir a mí 
territorio porque sos enemigo. Enemigo o sospechoso de serlo, si te vemos te caen los bombazos" (PMS-2)

III.2 Un horizonte político oscuro

A partir de 2009 el gobierno habló de prevención de la violencia pero sin instrumentalizarlo en un plan. Debe recordarse que fue el FMLN el principal partido opositor de las Manos Duras, ya que consideraban que la represión era contraproducente y el uso del ejército en tareas de seguridad violaba la constitución y los Acuerdos de Paz. Sin embargo, en el tema de prevención de violencia no se evidenciaron cambios.

"con la prevención famosa de Funes, que ni había prevención ni represión, es decir, no había nada. En la práctica, nada” (DH-1)

"Funes nos dijo que tendríamos trabajar con los niños, pero ¿sin medios?, ¿sin estrategia institucional? No, no. El ISNA no es un circo hay que formar a las personas y dotar recursos necesarios" (ISNA-1)

Sin un plan concreto de prevención de la violencia, los dos primeros años de gobierno siguieron la misma ruta de sus antecesores. Incluso, fue el FMLN quien militarizó las cárceles e incrementó el uso de efectivos militares en tareas de seguridad. Pero lo más relevante del tema de seguridad fue asignarle el Ministerio de Justicia y Seguridad a Munguía Payés, un militar que estaba a cargo del Ministerio de Defensa. El continuismo de la represión desencadenó el recrudecimiento de la violencia.

"Ya en el 2011 o 2010, Munguía Payés hablaba de crear leyes más duras, fiscales especiales y jueces especiales. Hablaba de entrar con las tropas a los territorios, el mismo discurso brasilero contra la violencia" (DH-1)

"Cito a Jeffrey; mas leyes, más fiscales, más policía, más cárceles implican más presos, pero no necesariamente menos delitos” (PU-1)

"Aquí no se ha hecho nada, nosotros seguimos controlando. ¿Vos les creés a los que salen en la tele diciendo que nos tienen acorralados? La mara se impone aquí y donde sea" (PMS-2)

Sin embargo, de forma repentina, las tasas de homicidios y los niveles de violencia se redujeron significativamente. Aunque algunos lo celebraban y el gobierno lo promovía como resultado de sus políticas de seguridad, fue gracias a una investigación del periódico digital El Faro que se supo de la existencia de una tregua entre las pandillas auspiciada por gobierno de Mauricio Funes. Fue un cambio brusco y repentino. Detrás de la tregua se encontraba el ministro de seguridad Munguía Payés. El mismo militar que estaba a favor de la represión y de crear leyes más duras contra las pandillas, estaba detrás de la tregua junto a otros dos personajes poco conocidos: el obispo castrense Fabio Colindres y el exguerrillero Raúl Mijango.

"Payés, después de su discurso belicista decide armar "la tregua". Es un cambio radical. Pasan de la prevención al arreglo con las pandillas” ( $\mathrm{DH}-1)$

“¿Vos creés que la tregua de Funes fue la única? Nosotros hicimos un vergo de treguas con ARENA, las hicimos hasta que Flores se cagó en todo y empezó a capturar masivamente” (PMS-1)

"La tregua fue un pacto, un bisne entre los de arriba y nosotros Nosotros bajamos los homicidios y ellos nos dejaron de joder" (PBS-1)

La tregua dejó muchas dudas acerca del manejo político de la violencia. El gobierno no aceptó abiertamente estar auspiciando la tregua; sin embargo, se acreditaba la reducción de los homicidios y la violencia.

"Si me preguntas a mí qué fue la tregua puedo decirte que fue una paz mafiosa. Es capitalizar el tema de los muertos para construir una fuerza política” (RT-1) 
"El PATI fue una mentira desde el principio, servía para darle dinero a los pandilleros. Hubo mucha corrupción, muchas cosas raras. Por eso es que no han funcionado los planes. Son arreglos que se hacen con las pandillas sin un acuerdo de estado y de los que nosotros no nos enteramos" (ORGF-1)

Muchos de los beneficios de la Tregua fueron para los líderes que se encontraban, la mayoría, en cárceles de máxima seguridad, lo que llevó a fragmentar la jerarquía y la organización de las pandillas. El liderazgo con el que contaban los líderes de las pandillas encarcelados se vio mermado.

"Los beneficios de la tregua de Funes fueron para los de arriba, los que están en el tabo. Los que pusieron a la Eighteen en grande, los que han llevado a la Grandota a ser lo que es, esos se llevaron los mejores beneficios, hey, eso dolió" (PBS-2)

"La tregua parece que ha democratizado las pandillas, a pesar que sigue funcionando el balazo al traidor" (FIS-1)

III.3 Fracaso anunciado: la política del Enfrentamiento Directo

El fracaso de la tregua y el incremento de la violencia influyeron en las elecciones presidenciales de 2014: ARENA y el FMLN se debatieron en una segunda vuelta, donde el segundo ganó por un corto margen de seis mil votos. El nuevo presidente, Sánchez Cerén, decidió apartarse de todo proceso de tregua y diálogo con pandillas y prometió que actuaría duramente contra los grupos criminales.

"El presidente lo dice de manera explícita: "No vamos a caer en el mismo error, no vamos a volver a negociar con las pandillas". Yo considero esto como el final de la "Tregua" y el inicio de lo que tenemos" (PER-1).

"Se acabaron las concesiones a los pandilleros. Hora de arremangarse" (COP-1)

"El gobierno puede negarse a dialogar, por eso no hay pedo, de todas formas la grandota va a seguir creciendo y tenemos que estar "víboras". (PBR-1)

Con la llegada de Sánchez Cerén al gobierno se definió una hoja de ruta a seguir en materia de seguridad. La respuesta de las pandillas fue incrementar los homicidios y la violencia hasta alcanzar cifras récord de homicidios para el año 2015.

"Mirá, ahorita nos están matando, nos están masacrando. La gente lo sabe y eso nos tiene dolidos, hey. Imagínate que alguien celebre cuando matan a alguien de tu familia” (PMS-2)

"muertos todos los días, a todas horas cuéntalo bien alto que los salvadoreños convivimos con la tragedia” (ORGF-1)

"Juras y ranas nos están masacrando. Lo peor es que se hace con apoyo del gobierno. Ya no disimulan como hacían antes cuando el "Frente" era oposición” (PMao-1)

Los dos primeros años del gobierno de Sánchez Cerén se han caracterizado por la represión; el incremento de operativos y detenciones; mayor presencia del ejército en patrullajes; pero lo más significativo han sido los enfrentamientos directos y las medidas especiales en las cárceles.

“¿Vos creés que las pandillas van a aguantar contra un batallón del ejército? Ya se han dado enfrentamientos, hay que acabar con las ratas”. (MJ-1)

"Ahora tenemos tres bandos: policías, militares y pandilleros en las calles, enfrentados entre ellos. Todo esto en un país sometido a muchas manos duras. La mano dura del Estado desalmado y criminal; la mano dura de las pandillas; la mano dura de la sociedad civil" (RT-1) 
"Estamos en una guerra, eso está claro. Lo que pasa es que está guerra es más cruel y más sangrienta que la que ya vivimos. Ahora muere más gente. Y no sólo es morirse, es desaparecer, es que te corten en cientos de pedazos" (POL-1)

Una sociedad como la salvadoreña, acostumbrada a convivir con la violencia y que ha naturalizado el accionar de los gobiernos frente a las pandillas, apoya y celebra las medidas represivas actuales.

"Como funcionario no debería de estarte diciendo esto pero creo que esta síque es una mano dura. Incluso, podría ser más dura La gente es lo que quiere, la gente lo que quiere ver es titulares de 10, 20 pandilleros muertos en un enfrentamiento con las pandillas" (MJ-1)

"El estado tiene la fuerza, pero no la legitimidad para acabar con las pandillas con abusos" (PU-1)

“Nos matan y rematan... y a nadie le importa” (PBR-1)

Los manodurismos fueron períodos violentos, sin embargo no pueden equipararse a los niveles de violencia que se han experimentado a partir del 2014. Los discursos de los informantes dan una representación de la afirmación anterior:

"Esto va a reventar, va a haber matazón. Aquí van a morir un vergo de juras y ranas, aquí va a correr sangre. No ahorita, ni mañana, pero vas a ver, cuando menos se lo esperen vamos a dar otro golpe en la mesa. Lo del paro del 2015 fue un chistecito, nosotros tenemos la mano de obra, tenemos vergo de homies listos a lo que sea" (PBR-1)

"Los gobiernos cuando ven serio el problema hacen una "limpieza"; primero matan a los cabecillas y luego más violencia. Esto también es un negocio. Lo que no entienden es que matar a un palabrero significa venganza para nosotros" (PMS-1)

"No creo que ningún Salvadoreño sienta orgullo de vivir este periodo de nuestra historia el gobierno utiliza la fuerza desproporcionada” (PU-1)

"matar pandilleros o hacerles desaparecer, no pone fin al problema a un perro de presa la sangre lo excita más” (ISNA-1)

El conflicto sigue vigente y no se prevé un cambio en el accionar del gobierno, al menos no hasta que se acerque el período electoral de cara a las elecciones presidenciales de 2019. En ese momento se vislumbrarán las estrategias de cada uno de los partidos, pero puede adivinarse que serán básicamente dos: más represión o pactos oscuros con las pandillas.

\section{Discusión}

Los objetivos para afrontar el trabajo se orientaron en examinar las políticas públicas orientadas a la violencia pandillera en El Salvador, además de identificar factores que han influido en el mantenimiento e incremento de la violencia y las pandillas. En este sentido, abordaremos los resultados obtenidos conjuntamente con la literatura científica, a efectos de establecer una discusión de los mismos.

IV.1 Fragilidad democrática de un estado vulnerable

Los informantes clave coinciden en que en El Salvador las políticas públicas implementadas contra la violencia de las pandillas no han seguido lo elementos básicos de políticas de calidad, sino que han sido influenciadas por factores ajenos al bien común. Se han aplicado cuatro políticas principales: Plan Mano Dura (2003), Plan Súper Mano Dura (2004), tregua entre pandillas (2012) y Enfrentamiento directo (2014-2019). El discurso de los entrevistados informó 
que aunque los gobiernos salvadoreños han promovido supuestas políticas públicas contra las pandillas, éstas no han cumplido las fases de una política pública y tampoco contienen los elementos básicos de una política pública de calidad. Contrario a esto, los gobiernos han basados sus políticas en respuestas mediáticas, populistas y escasamente planificadas. Esto, según Cruz (2000) desgasta la credibilidad de la población en las instituciones. El manejo de la violencia y la delincuencia pandilleril se ha caracterizado, según Amaya \& Martínez (2015), por pretender solucionar el conflicto a base de reformas penales, articulando normas cortoplacistas y asociadas a la represión.

Los últimos cuatro gobiernos han centrado su agenda de seguridad en torno a las pandillas, pero los informantes han destacado que no hubo un proceso de planificación, gestión y evaluación del conflicto, sino que todo ha sido motivado por los fines electorales. A este respecto, Surel (2006) denomina ciclo electoral, aquellas respuestas gubernamentales que destacan en el cambio de agenda política.

Los informantes señalan la ausencia de mecanismos capaces de orientar la política pública de seguridad de forma pacífica, y consideran que los actores involucrados deberían poder modificar o fortalecer las acciones gubernamentales. En su definición de política pública Gray \& Jenkins (2006) consideran necesaria la articulación de decisiones hilvanadas y asumidas por eslabones políticos, considerando los medios necesarios para alcanzar los objetivos, En esta línea, Olate, Salas \& Vaughn (2012) sostienen que el diseño y la implementación de las políticas en El Salvador no han considerado las características específicas de la juventud y de las comunidades, de ahí que las acciones que se emprendan no den los resultados esperados.

Otra elemento muy recurrente en las políticas salvadoreñas es el laissez faire. La administración de Mauricio Funes se caracterizó por esta práctica y su principal consecuencia fue la de mermar el papel de algunas instituciones del Estado, como en el caso del ISNA. Este Instituto no fue capaz de desarrollar plenamente sus objetivos y actividades debido a la poca priorización y a la disminución de recursos por parte del gobierno central. Otro caso de laissez faire fue sacar al ejército a las calles para participar en las tareas de seguridad, según Van der Borgh y Savenije (2015) y en la línea de los resultados presentados, uno de los principales cambios en el afrontamiento del conflicto y en el posterior recrudecimiento de la violencia.

De acuerdo a los informantes, la Mano Dura y Super manodura fueron motivadas por fines electorales y continuistas. Sobre esto, Bergmann \& Meléndez sostienen que "los planes y las leyes antimaras eran, sobre todo, inconstitucionales y curiosamente temporales, dictadas en períodos preelectorales" (2015, p. 118). Es decir, confluyeron estrategias electorales con acciones desligadas, discontinuas y desequilibradas. Las Manos Duras se centraron en la creación de leyes más duras contras las pandillas y las redadas y detenciones masivas. Siguiendo esta línea, Aguilar (2006) sostiene que los planes contemplaban reformas al código penal, endureciendo las penas contra ciertos delitos y facilitando el juicio y encarcelamiento de los jóvenes detenidos, y operativos para capturar pandilleros en todo el país. Los informantes clave consideran que las Manos Duras se centraron en aspectos puntuales, pero sus efectos contraproducentes fueron diversos.

La tregua de 2012, según los informantes, permitió reorganizar y fortalecer a las pandillas con la complicidad del gobierno, ya que en 2016 se comprobó que ésta, además de ser elaborada por el gobierno, estaba plagada de impunidad y corrupción por parte de los funcionarios involucrados (Cruz 2018; Roque 2017). Algunos informantes corroboran los beneficios y prebendas que dio la tregua para pandilleros y funcionarios. 
Después del fracaso de la tregua, el nuevo gobierno del FMLN, dirigido por Sánchez Cerén, tomó la decisión de acabar con todo proceso de diálogo y negociación con las pandillas y basó su política de seguridad en la represión, el enfrentamiento directo con las pandillas y el incremento de los efectivos militares en las calles. Además, se promovió una resolución constitucional para considerar a las pandillas como terroristas; según Zablah (2015), por atentar contra la vida y los derechos de la población. Coincidiendo con esta cuestión, Réserve (2016, p. 188), informa que "las noticias de enfrentamiento entre pandilleros y policías se ha vuelto una moneda corriente, y se ha transformado en la expresión de la nueva guerra y crisis de seguridad pública que vive El Salvador". Es decir, la ausencia de políticas bien fundamentadas y formuladas sin pretensiones más allá del bien común, permite la reproducción del crimen y el incremento de la violencia. Además, Mejías (2012), plantea que la falta de preparación del ejército en materia de seguridad pública podría desencadenar una serie de violaciones a los derechos humanos, algo que ya ha sido denunciado en El Salvador.

Las tres políticas anteriores (Manos Duras y Tregua) fracasaron y aparentemente el gobierno actual no consideró los aspectos negativos de éstas para no cometer los mismos errores. La represión del delito y la impunidad siguen como características negativas en la actual administración. En esta línea, Reguillo (2005, p. 79) sostiene que "la política punitiva extrema, el castigo ejemplar como liturgia de los tiempos «modernos", se enfrenta a la fortaleza de quien no tiene nada que perder, salvo la vida que, en los entornos empujados a la miseria por el capitalismo depredador, es un bien devaluado". Es decir, los pandilleros están dispuestos a matar y morir por algo que ellos consideran su causa.

Los gobiernos salvadoreños no han sido capaces de gestionar la seguridad pública y esto combinado un Estado democráticamente débil, favorece la presencia y fortalecimiento del crimen organizado. Este mismo factor, según Waldmann (2006), es un obstáculo para las instituciones como la policía y las que forman el sistema de justica que se ven superados por los constantes cambios en sus competencias y atribuciones.

Se ha establecido que El Salvador enfrenta graves problemas para diseñar políticas de seguridad pública (Gledhill 2013). Siguiendo esto, Wood (2009) plantea que el ciclo más adecuado en materia de seguridad pública debe basarse en un proceso gubernamental en el que, en primer lugar, se refleje las problemáticas; en segundo lugar, se incorporen a la agenda pública; en tercer lugar, se diseñen, implementen y gestionen acciones concretas; y finalmente se evalúen sus resultados. Esto significa llevar a cabo tres elementos primordiales, que de acuerdo a los informantes, no se han implementado en El Salvador: actualización situacional en torno a la criminalidad, el desarrollo de una agenda diagnóstica en materia de seguridad pública y una estrategia preventiva y de control del crimen (Vivas 2009).

\section{Conclusiones}

A partir de los resultados se puede afirmar que las políticas públicas en materia de seguridad han sido motivadas por pretensiones electorales y han centrado sus acciones en medidas populistas y mediáticas. Éstas políticas han tenido como elementos comunes la falta de consenso, la poca planificación, mucha oposición, ilegalidades y violaciones a los derechos humanos. Por otra parte, las cuatro políticas examinadas, es decir: Mano Dura, Súper Mano Dura, Tregua y Enfrentamiento Directo, han tenido en común dos efectos contraproducentes: incremento de la violencia y fortalecimiento de las pandillas. 
Los últimos cuatro gobiernos salvadoreños han implementado acciones, que aunque estrictamente pueden considerarse como políticas de seguridad pública, en la práctica distan de lo que autores como Lahera (2004) consideran como políticas públicas de calidad. Contrario a las fases de las políticas públicas, es decir: formulación, implementación y evaluación, lo que se ha hecho en El Salvador es promover leyes más duras contra las pandillas; militarizar la seguridad pública; realizar acciones mediáticas contra las pandillas; detener y encarcelar a pandilleros y jóvenes; establecer pactos oscuros con el crimen organizado y fomentar el uso de la fuerza excesiva en los cuerpos de seguridad.

La corrupción, la impunidad, el populismo, la falta de planificación, la poca capacidad de los líderes y gobernantes, la frágil democracia, un sistema judicial corrupto y débil, la militarización de la seguridad pública y la naturalización de la violencia por parte de la sociedad salvadoreña son sólo algunos de los elementos que han permitido el mantenimiento e incremento de la violencia.

Al inicio del presente artículo nos planteábamos necesidad de identificar la presencia de alternativas para superar la violencia. En este sentido y para finalizar, proponemos una serie de recomendaciones ajustadas a este escenario concreto de violencias complejas; propuestas para reducir sensiblemente la crisis social y política que vive El Salvador y que deben profundizar en:

- El fortalecimiento de las bases democráticas.

- Elaboración de una política pública de seguridad consensuada con diferentes actores de la sociedad, basada en respeto a los Derechos Humanos.

- Un pacto interpartidario para establecer una política pública de seguridad de mediano y largo plazo.

- La separación real de estamentos del estado y especialmente en la independencia del poder judicial respecto el ejecutivo.

- El abordaje integral del bienestar de la población mediante políticas reales que atiendan la mejora de la calidad de vida y seguridad de los salvadoreños.

- El diagnóstico territorial que incluya planes estratégicos y sostenibles para reducir la inseguridad y la extorsión.

- La articulación de leyes basadas en el diálogo y en la cooperación en contra de la violencia a partir de políticas cuyo objeto sea la creación de un pacto de estado contra la violencia institucional y contra la violencia de las pandillas.

- La abolición de monopolios tácitos en órganos de poder.

- El desarrollo de políticas de transparencia que operen en la concepción de ciudadanía democrática.

- La evaluación continua de las propuestas anteriores que permita reorientar cambios y adecuar las necesidades público-ciudadanas.

En definitiva, políticas públicas de consenso que integren como decíamos anteriormente, pactos de estado, con objetivos tangibles y herramientas para alcanzarlos. Políticas ajenas a los vaivenes del poder y a las influencias e injerencias de los lobbies de interés.

Alberto Martínez-Reyes (kemare@alumni.uv.es). Doctorando en el Programa de Desarrollo Local y Cooperación Internacional en la Universidad de Valencia. Máster en Cooperación al Desarrollo por la Universidad de Valencia. Licenciado en Relaciones Internacionales por la Universidad de El Salvador. Investigador del Observatorio Centroamericano de Desarrollo Social (OCADES), de la Secretaría de Integración Social Centroamericana (SISCA). 
José Javier Navarro-Pérez (J.Javier.Navarro@uv.es). Doctor en Desarrollo Local y Territorio con Premio Extraordinario de Doctorado por la Universidad de Valencia. Diplomado en Trabajo Social y Licenciado en Criminología. Profesor Contratado Doctor del Departamento de Trabajo Social y Servicios Sociales e Investigador del Instituto Interuniversitario de Desarrollo Local de la Universidad de Valencia (España).

\section{Referencias}

Aguilar, C. \& Lima, M. 2009. ¿Qué son y para qué sirven las Políticas Públicas? EUMED. Disponible en: www.eumed.net/rev/cccss/05/aalf.htm Acceso: 04.12.2019.

Aguilar, J. 2006. Los efectos contraproducentes de los Planes Mano Dura. Revista de pensamiento iberoamericano, 16, pp. 81-94. DOI: $10.2307 /$ j.ctt21pxk2m.16

Amaya, L. \& Martínez, J. 2015. Escisión al interior de la pandilla Barrio 18 en El Salvador: Una mirada antropológica. Revista de Policía y Seguridad Pública, 5(1), pp. 149-178. DOI: 10.5377/rpsp.v5i1.1987

Andrade, K. 2015. Las pandillas salvadoreñas y el delito de extorsión. Desafíos y prioridades en relación con el fenómeno extorsivo. Revista de Policía y Seguridad Pública, 5 (1), pp. 103-148. DOI: 10.5377/rpsp.v5i1.1986

Bergmann, A. \& Meléndez, O. 2015. Violencia en tiempos de paz: conflictividad y criminalización en El Salvador. San Salvador: Dirección Nacional de Investigaciones en Cultura y Arte, Secretaría de Cultura de la Presidencia.

Binford, L. 2002. Violence in El Salvador. A Rejoinder to Philippe Bourgois’s `The Power of Violence in War and Peace. Ethnography, 3(2), pp. 201-219 DOI: 10.1177/1466138102003002004

Briceño, R. \& Zubillaga, V. 2002. Violence and Globalization in Latin America. Current Sociology, Vol. 50(1), pp. 19-37.

Bruneau, T. 2014. Pandillas and Security in Central America. Latin American Research Review, 49 (2), pp. 152-172. DOI: 10.1353/lar.2014.0022

Cardozo, Myriam. 2013. De la evaluación a la reformulación de políticas públicas. Política y Cultura, 40, pp. 123-149.

Creswell, J. 2006. Qualitative Inquiry and Research Design: Choosing among Five Approaches. Califórnia: Sage Publications.

Cruz, J. \& Durán, A. 2016. Hiding violence to deal with the state Criminal pacts in El Salvador and Medellin. Journal of Peace Research, 53(2), pp. 197-210. DOI: 10.1177/0022343315626239.

Cruz, J. 2000. Violencia, democracia y cultura política. Nueva Sociedad, 167, pp.132-146.

Cruz, J. 2018. The Politics of Negotiating with Gangs. The Case of El Salvador. Bulletin of Latin American Research, 1-16. DOI: $10.1111 /$ blar.12847

Dammert, L. 2012. Seguridad ciudadana y cohesión social en América Latina. Barcelona: Programa URB-AL III.

Denzin, N. 1970. A qualitative approach. Califórnia: Sage Publications.

Dresser, D. 1998. Neopopulist solutions to Neoliberal problems. La Jolla, Ca. University of California, San Diego. Center for U.S- - Mexican Studies. Current Issues Brief, 3, pp.218-229.

El Salvador saca a la calle a sus soldados para combatir la delincuencia. 2009. La Prensa Gráfica. San Salvador 5 de nov. Disponible en: http://www.laprensagrafica.com/internacionales/latinoamerica/70977-el-salvador-saca-sussoldados-a-la-calle-para-combatir-la-delincuencia Acceso: 12.08.2017.

Garmany, J. \& Galdeano, A. 2017. Crime, insecurity and corruption: Considering the growth of urban private security. Urban Studies Journal, 55(3), pp. 1111-1120: DOI: 10.1177/0042098017732691

Gledhill, J. 2013. La mala administración de la seguridad pública. Revista de Antropologia Social, 22(0), pp. 25-57. DOI: 10.5209/rev_raso.2013.v22.43182

Gómez, J. 2013. El crimen organizado en las cárceles: Las extorsiones desde los centros penales en El Salvador (2008-2009). Policía y Seguridad Pública, 3(1), pp. 131-171. DOI: 0.5377/rpsp.v3i1.1333

Gray, A. \& Jenkins, B. 2006. From Public Administration to Public Management: Reassessing a Revolution?. En Eric E. Otenyo \& Nancy S. Lind. Comparative Public Administration. Reino Unido: Emerald Group Publishing Limited, pp. 543-572.

Hegre, H. 2014. Democracy and Armed Conflict. Journal of Peace Research, 51(2), pp. 159-172. DOI: $10.1177 / 0022343313512852$

Heinze, G. \& Armas, G. 2015. Public policies on the use of drugs in Mexico and Latin America. Drug Science, Policy and Law, 2, pp. 1-11. DOI: 10.1177/2050324515611587

Jolly, M. 2001. The Encyclopedia of Life Writing: Autobiographical and Biographical Forms. New York: Routledge.

Jütersonke, O., Muggah, R. \& Rodgers, D. 2009. Gangs, Urban Violence, and Security Interventions in Central America. Security Dialogue, 40 (4-5), pp. 373-397. DOI: doi.org/10.1177/0967010609343298

Kinosian, S.; Albaladejo, A.; \& Haugaard, L. 2016. La violencia en El Salvador: no hay una solución sencilla. Disponible en http://www.lawg.org/storage/documents/La_Violencia_en_El_Salvador.pdf. Acceso: 10.03.2017.

Lahera, E. 2004. Política y políticas públicas. Repositorio CEPAL. Serie 95, políticas sociales. Disponible en: http://repositorio.cepal.org/bitstream/handle/11362/6085/1/S047600_es.pdf. Acceso: 04.12.2019.

Layard, R. 1980. Human satisfactions and public policy. Economic Journal, 90 (360), pp. 737-750. DOI: 10.2307/2231740

LeBrón M. 2017. They Don't Care if We Die: The Violence of Urban Policing in Puerto Rico. Journal of Urban History, 1, pp. 1-20. DOI: $10.1177 / 0096144217705485$

LeGreco, M. \& Tracey, S. 2009. Discourse Tracing as Qualitative Practice. Qualitative Inquiry, 15 (9), pp.1516-1543. DOI: $10.1177 / 1077800409343064$ 
Lessing, B. 2017. Counterproductive punishment: How prison gangs undermine state authority. Rationality and Society, 29 (3), pp. 257-297. DOI: $10.1177 / 1043463117701132$

López, D., Quintanilla, S., \& Gómez, J. (2017). Las Pandillas: Su Expansión Territorial en El Salvador. 1992-2015. San Salvador: Colegio de Altos Estudios Estratégicos de El Salvador. Obtenido de http://www.caee.edu.sv/images/pdf/PANDILLAS.pdf Acceso: 04.12.2019

Martel, R. 2006. Las maras salvadoreñas: nuevas formas de espanto y control social. Estudios Centroamericanos, 61 (696), pp. 957-979.

Martínez-Reyes, A. \& Navarro-Pérez, J.J., 2018. ¿Atracción o reclutamiento? Causas que motivan el ingreso en las pandillas de los/as adolescentes salvadoreños/as. Revista Prisma Social, 23 (4): 19-45.

Medellín, P. 2004. La política de las políticas públicas: propuesta teórica y metodológica para el estudio de las políticas públicas en países de frágil institucionalidad. CEPAL, División de Desarrollo Social. Disponible en: http://repositorio.cepal.org/bitstream/handle/11362/6082/1/S047566_es.pdf Acceso: 04.12.2019.

Mejías, S. 2012. La participación militar en el combate contra la violencia criminal. Cuadernos de Estrategia, 158, pp. 196-232.

Meyer, P. \& Seelke, C. 2011. Central America Regional Security Initiative: Background And Policy Issues For Congress.Current Politics and Economics of South and Central America, 4 (4), pp. 721-766.

Milliken, J. 1999. The Study of Discourse in International Relations: A Critique of Research and Methods. European Journal of International Relations, 5(2), pp. 225-254. DOI: 10.1177/1354066199005002003

Muñoz, A. 2011. Book Review: No Place to Hide: Gang, State, and Clandestine Violence in El Salvador. International Criminal Justice Review, 21(3), pp. 315-327. DOI: 10.1177/1057567711409574

Olate, R., Salas, C. \& Vaughn, N. 2012. Predictors of violence and delinquency among high risk youth and youth gang members in San Salvador, El Salvador. International Social Work, 55(33), pp. 383-401. DOI: 10.1177/0020872812437227

Patton, M. 1990. Qualitative Evaluation and Research Methods. London: Sage Publications.

Peetz, P. 2010. Youth Violence in Central America. Youth and Society, 43(4), pp. 1459-1498. DOI: $10.1177 / 0044118 \times 10384236$.

Réserve, R. 2016. El Salvador: un año político y social convulso. Revista de Ciencia Política, 36 (1), pp. 177-194. DOI: 10.4067/s0718-090x2016000100008

Reguillo, R. (2005). La mara: contingencia y afiliación con el exceso. Nueva Sociedad, No. 200, 70-84.

Reyna, V. 2017. Estudio sobre las políticas de abordaje al fenómeno de las pandillas en El Salvador (1994-2016). Análisis (7), pp. 1-11.

Roque, S. 2017. Between New Terrains and Old Dichotomies: Peacebuilding and the Gangs' Truce in El Salvador. Contexto Internacional, 39 (3), pp. 499-520. DOI: 10.1590/s0102-8529.2017390300003

Sanjurjo, D. 2016. The role of defensive firearm use in the governance of security in Latin America. Theoretical Criminology, 21(3), pp. 324-341. DOI: 10.1177/1362480616654002

Santos, H. 2014. Las pandillas salvadoreñas y su comportamiento delictivo: Prospectiva de sus formas organizativas y expansión territorial para el próximo decenio 2015-2025. Policía y Seguridad Pública, pp. 183-225. DOI: 10.5377/rpsp.v4i2.1762

Savenije, W. 2014. Políticas de seguridad en El Salvador. Cuestiones de Sociología, 10, pp. 1-13

Speed, S. 2016. States of violence: Indigenous women migrants in the era of neoliberal multicriminalism. Critique of Anthropology, 36(3), pp. 280-301. DOI: 10.1177/0308275x16646834

Surel, Y. 2006. Relaciones entre la política y las políticas públicas. En F. Rolando \& L. Jorge. Política y Políticas públicas en los procesos de reforma de América Latina. España: Miño y Dávila. pp. 43-73.

Van der Borgh \& C. Savenije, W., 2015. De-securitising and Resecuritising Gang Policies: The Funes Government and Gangs in El Salvador. Journal of Latin American Studies, 47(1), pp.149-176. DOI: 10.1017/S0022216X14000741

Velásquez, R. 2009. Hacia una nueva definición del concepto "política pública". Revista Desafíos, (20), pp. 149-187.

Vilas, C. 2011. Política y Políticas Públicas en América Latina. En: Fioramonti, Cristina y Anaya, Paula (comps.). El Estado y las políticas públicas en América Latina. La Plata: AECID/COPPPALlHonorable Cámara de Senadores de la Provincia de Buenos Aires.

Vivas, R. 2009. La sobrevivencia como reto institucional. Mirador de Seguridad. Revista del Instituto de Estudios Estratégicos y Políticas Públicas, 1, pp. 127-30.

Waldmann, E. 2006. El Estado anómico: derecho, seguridad pública y vida cotidiana en América Latina. Buenos Aires: Editorial Iberoamericana.

Wodak, R. \& Meyer, M. 2009. Methods of critical discourse analysis. Thousand Oaks: Sage Publishing.

Wood, E. 2005. Challenges to Political Democracy in El Salvador. En F. Hagopian \& S. Mainwaring. The Third Wave of Democratization in Latin America: Advances and Setbacks. New York: Cambridge University Press. pp. 179-201.

\section{Otras Fuentes}

Programa de las Naciones Unidas para el Desarrollo (PNUD). 2013. Informe sobre Desarrollo Humano El Salvador 2013. Imaginar un nuevo país. Hacerlo posible. Diagnóstico y propuesta. San Salvador: Programa de las Naciones Unidas para el Desarrollo. Disponible en: <https://www.sv.undp.org/content/el_salvador/es/home/library/hiv_aids/informe-sobre-desarrollo-humano-el-salvador-2013.html>. Acceso: 04.12.2019 
Comisión Española de Ayuda al Refugiado (CEAR). 2013. “Maras en Centroamérica y México”. CEAR.ES Disponible en: $<$ https://cear.es/wp-content/uploads/2013/10/CENTROAMERICA.-2013.-Maras.pdf>. Acceso: 04.12.2019.

\section{From "Mano Dura" to "Enfrentamiento Directo": swings of public policies in El Salvador}

ABSTRACT Introduction: The articles analyses the four most important policies on public safety against gangs in El Salvador: Mano Dura (2003-2004), Súper Mano Dura (2004-2009), Tregua entre pandillas (2012-2014) and Enfrentamiento Directo (2014-2019). It aims to identify the impact of these policies on violence. Materials and Methods: The article is based on a qualitative research supported by 12 interviews and by life report with which it explores governmental responsibilities for violence problem in El Salvador. The fieldwork was accomplished in seven months, between September 2016 and March 2017. Data were processed through software MAXqda 12. Results: The research finds 1) the influence of electoral ambitions of the decision-makers on the formulation of policies; 2) the poor planification and discussion on the impact of governmental actions; and 3) the complex political and social scenario El Salvador will face. Discussion: based on these results and comparing them with the findings by scientific literature on the subject, the article supports the informants' statements according to which the four implemented policies have failed due to El Salvador's democratic fragility, to electoral ambitions of the political party in power and to poor capacity in designing good policies. The four implemented policies have had counter-productive effects and have made feasible the expansion and reorganization of gangs and the deepening of violence.

Keywords: Public policy; violence; gangs; public safety; El Salvador.

This is an Open Access article distributed under the terms of the Creative Commons Attribution Non-Commercial License which permits unrestricted non-commercial use, distribution, and reproduction in any medium provided the original work is properly cited.

A produção desse manuscrito foi viabilizada através do patrocínio fornecido pelo Centro Universitário Internacional Uninter à Revista de Sociologia e Política. 


\section{Glosario de conceptos de la jerga pandilleril insertados en los verbatios}

Bichos: niños y jóvenes.

Bisne: proviene del inglés "Business", negocio.

Bombazos: disparos de arma de fuego.

Chota: policía.

Clica: célula armada.

Darnos mecha: matarnos.

Desvergues: problemas.

Grandota: hace referencia a la pandilla 18 .

Hommies: pandilleros.

Huevean: roban.

Juras: policías.

Líneas: órdenes, directrices, etc.

Morrito: niño.

Palabrero: cabecilla.

Paloma: difícil, complicado, etc.

Pedo: problema.

Ranas: soldados.

Socados: presionados.

Tabo: cárcel.

Vergo: mucho, bastante, etc.

Víboras: preparados, listos. 